\title{
Nuevas políticas sociales \\ y Estado social relacional
}

Pierpaolo Donati

Universidad de Bolonia

RESUMEN

Según el autor, las sociedades europeas siguen inspirando las políticas sociales en un código (estatal) de inclusión —al que aquí se denomina lib/lab (mezcla de liberalismo y laborismo) — que en el pasado ha constituido un factor de progreso, pero que actualmente resulta cada vez más débil y obsoleto. Las políticas sociales encuentran límites estructurales en sus posibilidades de innovación porque están formuladas como compromisos entre Estado y mercado, utilizando al sector terciario para remediar los fracasos de los otros dos sectores. De hecho, los sistemas sociales gobernados por lógicas lib/lab se encaminan a una crisis irreversible. El documento ilustra las nuevas tendencias de configuración de las políticas sociales, que aquí se denominan «societarias». Se caracterizan por dos novedades principales: primero, por el hecho de que confían la inclusión social a una ciudadanía compleja (concebida como entrelazamiento de ciudadanía estatal y ciudadanía societaria), en la cual poseen un papel primordial los sujetos colectivos de la sociedad civil; segundo, porque definen el Bienestar, los servicios y los derechos sociales mediante un código simbólico de tipo relacional. En términos de orden institucional, se trata de pasar a un «cuarto modelo de Estado del Bienestar», es decir, a un Estado social de cuarta generación, después de haber dejado atrás el paternalista, el asistencial y el intervencionista. El autor lo denomina Estado social relacional.

Palabras clave: Política Social, Ciudadanía, Inclusión Relacional, Estado Social Relacional. 


\section{1. ¿ES POSIBLE INNOVAR LAS POLÍTICAS SOCIALES EN EUROPA?}

1.1. Las políticas sociales en Europa no se arriesgan a producir verdaderas innovaciones, sino que siguen adelante con lógicas anticuadas que dan continuidad a los modelos tradicionales de tipo asistencial. ¿Es posible generar innovaciones? La tesis de esta aportación es que sí es posible, pero a condición de asumir una concepción diferente de las políticas sociales, que denomino «relacional», y que presupone una visión nueva de las relaciones entre sociedad civil y Estado.

Respecto al resto del mundo, y en particular respecto a Norteamérica, las sociedades europeas se caracterizan por haber creado un significativo y potente Estado del Bienestar. A pesar de la diversidad de los diferentes «modelos» existentes en Europa (modelo escandinavo, británico, jacobino-francés, bismarckiano-alemán, mediterráneo y otros más), la tradición europea - a partir del siglo XVII - siempre ha confiado al Estado, concebido como Vértice y Guía de la sociedad, la función de asegurar el bienestar de la población.

Este Estado (social o del Bienestar) ha crecido durante la época moderna, y ha disfrutado de su apogeo en la segunda postguerra del siglo xx (con el denominado modelo keynesiano-beveridgiano, de fuerte connotación neocorporativista democrática).

Con la crisis de la modernidad, que incluye la crisis de la sociedad industrial y del Estadonación, el Estado del Bienestar ha entrado en una fase histórica de crisis, que exige replanteamientos y reformas en profundidad (Koslowsky y Follesdal, 1997).

Se ha hablado de un Estado del Bienestar postfordista, postindustrial, postbeveridgiano, y también de un paso del Estado del Bienestar a la Sociedad del Bienestar, incluso a través de formas de Atención en la Comunidad (community care). Por último, hoy en día se habla de tendencias hacia la «americanización» del Estado social europeo (sobre todo en el sentido de la introducción de planes de seguros privados en todos los sectores sociales).

Los fenómenos de pérdida de soberanía estatal, bien sea «hacia arriba» (debido a los procesos de globalización y, en parte, al proceso de unificación europea), bien sea «hacia abajo" —debido a las exigencias de más competencias por parte de las comunidades locales y de los movimientos de reivindicación popular (grass roots movements) — han hecho que el panorama resulte más complejo.

Nos preguntamos: ¿es posible introducir cambios significativos en las políticas sociales que sirvan para enriquecer la calidad de vida y las capacidades del bienestar de la sociedad más allá de los límites de la no-sostenibilidad de los modelos actuales? Y ello, ¿en qué forma, con qué valores e instrumentos, en qué direcciones? 
En esta aportación quisiera exponer la hipótesis de que hoy es posible una verdadera innovación de las políticas sociales si se adopta una nueva visión del Estado social, que denominaré «Estado relacional».

1.2. En la presente aportación intentaré aclarar esta perspectiva a través de los siguientes pasos. En primer lugar, intento explicar cuál es la diferencia entre el código estatal y el código relacional de la inclusión social en las políticas sociales, y por qué razón y de qué forma se hace hoy necesario el paso de uno a otro.

En segundo lugar, describo la alternativa que se da actualmente en las estrategias de política social entre los modelos lib/lab y los modelos societarios.

Finalmente, me propongo esbozar a grandes rasgos las características del Estado social de «cuarta generación», que denomino relacional.

\section{LAS SEMÁNTICAS DE LA INCLUSIÓNY LAS POLÍTICAS SOCIALES: DEL CÓDIGO ESTATAL AL CÓDIGO RELACIONAL}

2.1. Con el paso al siglo xxı, la Unión Europea se ha orientado decididamente a afrontar los problemas de las nuevas pobrezas, marginaciones y desviaciones sociales a través de políticas públicas de creciente «inclusión social» (Comisión Europea, 2002). Nuestro problema consiste precisamente en saber lo que significa y cómo se persigue.

Existen muchas maneras de entender la inclusión social, e incluso, dentro de un mismo código de significados, hay muchas maneras de volverla operativa y ponerla en práctica. En líneas generales, la inclusión indica en cualquier caso una pertenencia, un reconocimiento, un criterio de selección. Por ello, inclusión significa la posibilidad de acceder a un sistema societario cuando se reúnen determinadas características. El hecho de indicar que se posee una determinada propiedad o cualidad significa trazar una distinción respecto de quien no la posee (y que, por lo tanto, queda excluido) (Luhmann, 1995). Cabe preguntarse: ¿cuál es el código semántico de la inclusión en las políticas sociales?

Para la modernidad, la inclusión social es la plena pertenencia al Estado del Bienestar nacional, es decir, gozar de pleno acceso al conjunto de derechos y deberes de la ciudadanía social. Este tipo de inclusión puede conseguirse de varias maneras: i) a través de las titularidades de beneficios (entitlements) otorgados a los poseedores de derechos de ciudadanía, o ii) bien a través de apoyos, para que todos puedan participar en la competición por los recursos sociales, en base a una estructura generalizada de igualdad de oportunida- 
des. Así pues, inclusión social significa la posibilidad de concurrir a la obtención de mayores ventajas por el hecho de pertenecer a un determinado Estado nacional, gozando de sus formas de protección social.

Éste es el moderno código de la inclusión, que ahora se halla en crisis por una serie de factores. En especial, a causa de las dificultades de realizar la inclusión a través de la ampliación de derechos y aplicar una efectiva estructura de igualdad de oportunidades en la participación competitiva. Estas dificultades se reconducen a dos grandes procesos: la reversibilidad de los criterios y el mayor entrecruzamiento (crossing) de los límites atribuidos a las distinciones que definen los dos ámbitos, el de los incluidos y el de los excluidos. Quien estaba incluido puede, de repente, encontrarse excluido. Muchos incluidos en un sector de beneficios quedan excluidos de otros beneficios, etc. El Estado funciona como una «institución de la arbitrariedad» (Willke, 1999). Puede desaparecer un criterio de pertenencia y surgir otro distinto. Se puede estar incluido para ciertos aspectos, pero no para otros. La complejidad se acentúa por el hecho de que cada modo de incluir conlleva una pluralidad de formas de exclusión, que no pueden subsanarse basándose en el principio que las ha generado. Por ejemplo, incluir a través de una cierta garantía de renta mínima puede llevar a excluir a su beneficiario del trabajo, de la adopción de ciertas iniciativas o del uso de determinadas oportunidades, exclusiones que no pueden remediarse con ulteriores garantías de renta. $\mathrm{O}$, viceversa, incluirle en la sociedad dándole un trabajo garantizado puede llevar al beneficiario a excluirlo de ciertos cauces de actuación que podrían aumentar su renta y permitirle la adopción de determinadas actividades o servicios.

Todo ello pone en crisis el moderno código de la inclusión social y genera el postmoderno, que se caracteriza justamente por la posibilidad de que los criterios de inclusión/exclusión resulten reversibles o puedan transformar a los incluidos en excluidos.

Pero no se trata sólo de esto. En la condición postmoderna surge otra situación: se da el hecho de que las distinciones de pertenencia pueden cambiar radicalmente el criterio rector. Si varían las distinciones-directrices en las que se basa la inclusión/exclusión, entonces el código de la inclusión ya no es moderno o postmoderno, sino trans-moderno. Ello tiene lugar, por ejemplo, cuando los criterios de inclusión hacen referencia a una pertenencia (membership) que no es la de la ciudadanía estatal, sino la de la pertenencia a grupos sociales autoorganizados (Falck, 1994; Lichterman, 2002). La inclusión se produce no bajo la égida del conjunto de la ciudadanía moderna, sino bajo la égida de una pertenencia más o menos seleccionada a contextos multicéntricos de tipo asociativo.

Por tanto, nos encontramos con nuevos códigos de la inclusión/exclusión diferentes de los modernos, y también de los postmodernos. Los denomino «tras-modernos» para subrayar 
que sus distinciones-guía presentan serias discontinuidades con la modernidad, pero que no están dominadas por la indeterminación y el relativismo (como en el llamado postmoderno). En gran parte, se trata de códigos más latentes que manifiestos, los cuales modifican en sentido del espacio público y redefinen los modos de la inclusión social en términos que ya no corresponden a la estatalidad moderna, sino que son multicontextuales (por seguir a Teubner, 1999), es decir, que reflejan diversos códigos para cada contexto.

Del código de la inclusión/exclusión estatal se pasa al código que denomino relacional/norelacional, es decir, que se está incluido en una política social no por el mero hecho de pertenecer a un Estado, sino por formas de pertenencia más generales que valoran contextos relacionales, aunque no sean estatales.

La característica fundamental del nuevo código simbólico que orienta las políticas sociales consiste en que la inclusión no se produce como forma de protección por parte del Estado social (cuando dice «te concedo o no te concedo un determinado beneficio social»), sino que tiene lugar como forma de relacionamiento del individuo según un código multidimensional y morfogenético que diferencia las pertenencias y los derechos-deberes, o los costes-beneficios, de las pertenencias individuales, por ejemplo las familiares. El relacionamiento ya no es dicotómico (quedas incluido o excluido), sino que es objeto de una expresión relacional, lo que significa que un sujeto puede ser incluido en determinados aspectos y no en otros, bajo determinadas condiciones, en relación con una determinada situación y un cierto tiempo.

A ello corresponde un cambio en el código de la «normalización». En la modernidad, el código de la normalización es de tipo estadístico, o sea, que tiene lugar como ampliación de un cierto intervalo —en torno a la moda - de la distribución estadística gausiana de las situaciones y de los comportamientos admitidos y titulares de reconocimientos y beneficios. Se observa que el proceso capitalista produce pobreza, desigualdad, marginación, desviación, y nos planteamos el problema de hasta qué punto son aceptables estas situaciones. La tendencia a incluir se produce como proceso de «normalización» de estas situaciones, haciendo extensivas a las mismas de ciertas medidas que posibiliten su inclusión en la norma de la distribución de los recursos (un proceso que, en general, no ve las exclusiones que él mismo genera). Sólo quien no quiere integrarse queda marginado (lo que es como decir que no se deja «normalizar»).

En el código trans-moderno, la normalidad no puede entenderse de este modo, ya que falta la idea de que las situaciones y los comportamientos sociales pueden estandarizarse (o bien compararse con una moda estadística). En una situación de creciente fragmentación, individualización y complejidad, la normalidad debe redefinirse. Ante todo, se plantea el 
problema cultural del reconocimiento de la especificidad de una situación y de un tratamiento relacionalmente adecuado (es decir, adecuado a la definición relacional de dicha situación o comportamiento). La normalidad resulta un problema de adecuación relacional al «caso concreto». Las políticas familiares son un campo emblemático de este cambio (Donati, 2003).

El código relacional nace y se desarrolla para sustituir los fracasos del código de inclusión estatal (lib/lab), pero no es ésta su función o su característica principal. De hecho, conlleva otro modo de concebir las políticas sociales ${ }^{1}$.

El código relacional tiene como principio rector observar si la medida de política social que pretende incluir a ciertos sujetos en el sistema societario genera, en realidad, su exclusión. $Y$ verifica este extremo observando los efectos en términos de relaciones, porque aplicar un derecho individual no quiere decir que vaya en beneficio de las relaciones sociales que posee una persona.

Por ejemplo, una prestación por maternidad puede darse con la intención de incluir socialmente a la mujer en un sistema de protección social. El código de inclusión se considera satisfecho si se aprueba una ley en tal sentido. El código relacional va más lejos: observa si esta medida crea efectivamente relaciones de solidaridad o si, en cambio, tiene por resultado aislar a la mujer. En el segundo caso, replantea la medida mirando la posibilidad de aplicarlo de otro modo, por ejemplo mediante un mundo asociativo en vez de mediante prestaciones impersonales y anónimas, contextualizando dicha medida en una red comunitaria.

El código relacional tiene por objetivo realizar la que se ha dado en denominar «ciudadanía profunda» (deep citizenship: Clarke, 1996), es decir, una ciudadanía concreta y contextualizada en una comunidad peculiar.

Éste intenta poner remedio a los límites e insuficiencias del código de la inclusión lib/lab, en el cual muchas de las prestaciones sociales (welfare benefits) incluyen a los individuos en un cierto sistema de garantías (por ejemplo, de renta mínima), pero les aíslan desde el punto de vista de las relaciones (familiares o sociales más amplias).

Los códigos no-relacionales se preguntan «quién» debe ser incluido (según reconocimientos, selecciones e indicaciones de mérito y de pertenencia estatal) y, por tanto, excluyen a quienes no reúnen tales requisitos. Los códigos relacionales se preguntan «cómo» incluir a cada persona y familia (según criterios de reconocimiento de la dignidad humana), para

1 El lector puede comprobarlo comparando los ocho indicadores en el esquema 3 de Donati (2002). 
que la vía de la pertenencia relacional represente una forma más amplia y mejor de aplicación de los derechos humanos fundamentales. Por tanto, mientras que los códigos no-relacionales convierten en funcionalmente equivalentes los contextos de solidaridad, los códigos relacionales califican tales contextos en base a las calidades relacionales que presentan y, por consiguiente, tienden a generar y promover solidaridad, mientras que los modelos no-relacionales «consumen» solidaridad.

2.2. Los dos códigos simbólicos (la lógica de inclusión de la ciudadanía lib/lab y la lógica relacional de la ciudadanía societaria) poseen una correlación en dos grandes escenarios, que son al mismo tiempo dos modos de contemplar los problemas sociales y de expresas propuestas alternativas de actuación operativa en clave de inclusión/exclusión. Denominaré a estos dos escenarios, respectivamente, «sistémico» y «societario».

I) El escenario sistémico, en esencia, viene a decir: las sociedades occidentales son cada vez más sistemas que funcionan en base a la primacía de una diferenciación que opera según el principio funcional de la inclusión lib/lab. Como tales, nuestras sociedades no distinguen entre comportamientos (e instituciones) normales y desviados, fisiológicos y patológicos, sino que observan, juzgan y tratan comportamientos e instituciones en términos de equivalentes funcionales, incluso para resolver el problema de la inclusión social. Conceden un número creciente de libertades a los individuos (línea lib) a cambio de la aceptación de reglas mínimas de conducta expresadas en términos de la ideología de las mismas oportunidades (igualdad de oportunidades para que todos gocen de las mismas libertades, a condición de no lesionar las mismas libertades de los demás). Las libertades se conceden siempre que no funcionen sobre la base de distinciones que etiqueten los comportamientos y generen discriminaciones (politically correct). Como tales, las libertades no implican tanto la autorresponsabilización de los sujetos y de sus redes de solidaridad social como más bien un sistema de controles encaminados a garantizar que funcione de forma efectiva el principio de la igualdad de oportunidades concedidas a los «individuos casuales» (línea lab). Por este motivo los denomino sistemas lib/lab.

II) En cambio, el escenario societario viene a decir: sin duda, la perspectiva sistémica lib/lab recoge algunos aspectos centrales de la forma en que funcionan realmente los sistemas occidentales, tanto en la forma de gobernar como en su legitimación cultural. Sin embargo, esconde dos cosas: primero, esconde el lado oscuro de dicho funcionamiento (existen esferas sociales que no operan sobre bases funcionales, que están exentas de esas modalidades o que se sustraen a ellas); en segundo lugar, esconde los resultados sociales que surgen a medio-largo plazo (nuevas exclusiones), y que no coinciden en absoluto con los auspiciados por el modelo lib/lab. La progresiva reversibilidad entre normalidad y desviación, su continuo entrecruzamiento, debilitan los potenciales de civilización. Las polí- 
ticas sistémicas planteadas sobre objetivos y criterios de reducción del daño no tienen ninguna esperanza ni de poder continuar en el tiempo ni de producir resultados que sean controlables, ni siquiera dentro de ciertos límites. Más bien generan sucesivas patologías, que el sistema no puede englobar, si no es al precio de perder las connotaciones de civilización que todavía le reconocemos y que todavía (pero ¿por cuánto tiempo?) legitiman el propio orden lib/lab (Luhmann, 1996).

Si se quiere salir de la impotencia de los sistemas lib/lab y de su continua generación de efectos perversos, es preciso contemplar como realidad de «sociedad civil» alternativas a las lógicas y a las políticas de sistema basadas en el principio asociacionalista (asociationalism) (Hirst, 1999). Me refiero al variado mundo de lo privado social (sector terciario), es decir, al mundo de las asociaciones sociales, del voluntariado, de las fundaciones sin ánimo de lucro, de la cooperación de solidaridad, de los bancos éticos, de los «bancos de tiempo", de las nuevas redes de mutualidades y, en general, al mundo de las formaciones societarias intermedias multicontextuales.

Estas realidades existen, incluso se difunden, pero no tienen voz ni poder ni recursos adecuados, porque los sistemas lib/lab están construidos en base a su exclusión. A veces las excluyen a priori, pero la mayoría de las veces las incluyen volviéndolas marginales en su propio seno (como ocurre en los procesos actuales de colonización del sector privado social por obra del Estado y del mercado). El reconocimiento y la valorización de las soluciones «civiles» implica el paso de «políticas de sistema» (estatales) a «políticas societarias» (relacionales), lo que puede tener lugar únicamente por medio de selecciones evolutivas que consisten: i) en la no-aceptación de la reversibilidad entre normalidad y patología; ii) en la afirmación de que la normalidad no es un parámetro preestablecido y objetivable en sentido positivista (ni tampoco es un resultado), sino que es una relación de adecuación a las necesidades humanas, que se plasma en contextos relacionales concretos y particulares, por distinción frente a modos de inadecuación relacional.

Mi tesis, en pocas palabras, dice que las estrategias de cohesión social pueden resultar más eficaces, equitativas y solidarias si reducen la lógica sistémica lib/lab a favor de las lógicas societarias que son propias de esos mundos asociativos en los cuales están vigentes los criterios: a) de la no-equivalencia entre normalidad y patología, y b) de la adecuación relacional de las intervenciones a las necesidades del mundo vital de las personas. Allí donde tales criterios funcionan de manera efectiva, se entiende lo que ocurre cuando la asociación existe y opera con eficacia para una mejor calidad del Bienestar. De hecho, la lógica societaria tiene requisitos que respetar. Implica la adopción de algunos criterios éticos comunes en la esfera pública, que son básicamente tres: el reconocimiento de los derechos humanos, el carácter solidario (que produce socialidad) del papel 
civil que las formaciones sociales intermedias desempeñan y su gobierno interno de tipo democrático.

\section{3. ¿QUÉ POLÍTICAS SOCIALES DE CIUDADANÍA? ESTRATEGIAS LIB/LAB FRENTE A ESTRATEGIAS RELACIONALES}

3.1. Frente a la extendida crisis imperante y cada vez más agudizada del Estado del Bienestar, las sociedades occidentales deben hacer frente a los siguientes dilemas:

a) Garantizar más libertades a los ciudadanos, pero al mismo tiempo responsabilizarlos más por las consecuencias de sus comportamientos privados.

b) Garantizar más autonomía (autogestión) en las esferas sociales intermedias, pero al mismo tiempo orientarlas hacia el bien común.

c) Garantizar más seguridad social, pero evitar la burocratización de la sociedad.

d) Garantizar la igualdad social, pero también el respeto de las diferencias legítimas (por ejemplo, culturales y de género).

e) Elaborar criterios de legitimación de las diferencias en las identidades y en los comportamientos (que se construyen cada vez más fuera de la naturaleza).

f) Responder a las exigencias de los individuos, pero también favorecer la solidaridad entre las personas.

g) Abrirse a la globalización, pero también responder a las exigencias locales.

Parece que se pretenda la cuadratura del círculo. Y, sin embargo, éstas son las líneas de fuerza de los actuales procesos históricos, más allá de los diversos enmascaramientos ideológicos. Podemos resumir estas tendencias diciendo que el «nuevo» Estado del Bienestar debe hacer frente a un dilema de fondo: debe permitir más diferenciación social, pero también asegurar una mayor integración social. Debe desestatalizar la sociedad, pero debe ofrecer también más coordinación y directrices políticas encaminadas al bien común de toda la sociedad interesada. En resumen: debe adoptar cauces de actuación que impliquen decisiones éticas. Ya se ha terminado el paradigma mandevilliano del Estado del Bienestar, según el cual los vicios privados pueden coexistir con las virtudes públicas. Se ha terminado el modelo nacional del Estado social (aunque todavía hoy hay quien pide «na- 
cionalizar» el Estado asistencial). El Estado social ya no puede intervenir cuando y donde su intervención crea dependencia social.

La cuestión es la siguiente: ¿puede el Estado del Bienestar de derivación moderna salir de la crisis por medio de estrategias basadas en el principio lib/lab de inclusión? Mi respuesta, en líneas generales, es negativa, porque el Estado del Bienestar moderno — sobre todo en Europa- ha crecido justamente sobre el presupuesto de la neutralización de la ética, o, lo que es lo mismo, sobre la neutralización ética del principio de inclusión.

Para comprender el alcance de esta observación, baste recordar el hecho de que el conjunto de las intervenciones del Estado del Bienestar se ha convertido, por razones intrínsecas y dilatadas en el tiempo que sería largo enumerar, cada vez menos universalista e incondicional, y cada vez más selectivo y condicional (ver la figura 1).

Desde el punto de vista sociológico, la elección de los criterios que caracterizan las medidas sociales (universalista/selectivo, incondicional/condicional, que conforman las casillas 1 a 4 de la figura 1) no es indiferente en cuanto al tipo y grado de vinculación social que dichas intervenciones sociales crean entre el beneficiario y la comunidad que le rodea.

Según algunos, cuanto más se pasa de la primera a la cuarta casilla, tanta menos solidaridad y vinculación social se produce entre los asociados. Sin embargo, en la práctica, la correlación entre tipo de intervención y los resultados correspondientes a las ligazones sociales depende de una serie de «condiciones del entorno» más complejas. En otros términos, los diversos tipos de intervención producen una mayor o menor solidaridad social en función de que el modo de prestar dichos servicios sea más o menos relacional, con independencia de quién los presta (sea el Estado u otros actores).

Como han demostrado algunas investigaciones de tipo teórico y empírico, en general, pasar de medidas universalistas e incondicionales a medidas selectivas y condicionales por parte del Estado erosiona el sentido y la fuerza objetiva de los vínculos sociales entre personas y grupos sociales. Por poner un ejemplo, cabe recordar la crítica que A. Caillé y otros (1997) han dirigido a la renta mínima de inserción (RMI) tal como se ha aplicado en Francia tras la ley instituyente de 1988. Se trata de una medida selectiva y condicional que no sólo no se consigue aplicar correctamente (pocos llegan al contrato o el contrato se concluye con hipocresías y cláusulas fingidas por ambas partes), sino que comporta la desintegración de los vínculos sociales entre el beneficiario y su comunidad, más bien que lo contrario. En el Estado del Bienestar universalista e incondicional —sostiene Caillé al hilo de M. Mauss - subyacía la ética de la donación y, por tanto, la creación de la vinculación social. A medida que nos hemos ido alejando de este modelo, y ello ocurre de forma cada vez 
Tipos de intervenciones sociales según los criterios que los inspiran en el tratamiento

del beneficiario

\begin{tabular}{|c|c|c|}
\hline \multirow[b]{2}{*}{ Criterio económico } & \multicolumn{2}{|c|}{ Criterio político } \\
\hline & $\begin{array}{c}\text { Incondicional } \\
\text { (no se exigen obligaciones } \\
\text { al beneficiario) }\end{array}$ & $\begin{array}{c}\text { Condicional } \\
\text { (se exigen determinadas } \\
\text { obligaciones al beneficiario) }\end{array}$ \\
\hline $\begin{array}{l}\text { Universalista (beneficio otorgado } \\
\text { por el simple hecho de que un } \\
\text { individuo se encuentre en una } \\
\text { determinada condición de necesidad) }\end{array}$ & $\begin{array}{l}1 \\
\text { Ej.: subvenciones familiares } \\
\text { (en muchos países, no todos) }\end{array}$ & \begin{tabular}{l}
\multicolumn{1}{c}{3} \\
Ej.: previsión social basada \\
en contribuciones
\end{tabular} \\
\hline $\begin{array}{l}\text { Selectivo (beneficio otorgado } \\
\text { a un individuo que se encuentre } \\
\text { en una condición de necesidad y sólo } \\
\text { si no dispone de medios para hacerle } \\
\text { frente; uso del test de recursos } \\
\text { (means test) }\end{array}$ & $\begin{array}{l}\text { Ej.: subsidios de desempleo } \\
\text { Ej.: asignación por maternidad } \\
\text { o cuidado a terceros (care) }\end{array}$ & Ej.: RMI (renta mínima de inserción) \\
\hline
\end{tabular}

más extensa en todos los países, la ética de la donación resulta gravemente mutilada y sacudida, de forma que las intervenciones sociales terminan por producir — de modo no intencionado y paradójico- una mayor desintegración social. A mi entender, en cualquier caso, ello depende también del hecho de que quien ejecuta tales intervenciones no lo hace con la intención y los instrumentos apropiados para crear nuevas relaciones de solidaridad (circuitos de donación horizontal entre las personas y su comunidad, y no sólo de donación vertical entre Estado e individuos).

El Estado del Bienestar habla actualmente el lenguaje de la inclusión social (el eslogan es el de un desarrollo económico que favorezca la cohesión social), pero en realidad produce justamente lo contrario, la exclusión social, a través de medidas cada vez más selectivas y condicionales que exigen comportamientos paradójicos a los potenciales beneficiarios.

Por poner un ejemplo, en el caso de la renta mínima de inserción, la conminación paradójica es que «quien no tiene trabajo debe trabajar», es decir, se obliga a hacer lo que no se puede hacer, o en cualquier caso se le conmina, con independencia de la elección de la actividad, si la persona en cuestión no quiere ser considerada ociosa y, por tanto, quedar excluida de la sociedad. Así, las obligaciones que el beneficiario contrae resultan no solamente dudosas y generadoras de angustia, sino incluso estructuralmente marcadas por una doble obligación, lo que erosiona la vinculación social, anula la espiral de la donación $y$, con ello, el fomento del comportamiento ético. 
Dicho resultado puede evitarse cuando la solución selectiva y condicional de las intervenciones del Estado del Bienestar se exprese en términos de una nueva contractualidad relacional, es decir, vinculando los beneficios a contratos que fomenten la creación de relaciones de solidaridad entre los beneficiarios y entre éstos y los proveedores de servicios (mediante empresas sociales). Pero las actuales políticas sociales no conocen de contratos relacionales ${ }^{2}$ ni pueden gestionarlos, porque el sentido relacional de los contratos es precisamente lo que ésas han pretendido anular. De ahí que se esté en un callejón sin salida: el Estado del Bienestar puede salirse de la perversidad del principio de inclusión perseguido con tales medios sólo a condición de negar su propia finalidad. En cualquier caso, el principio político abstracto de inclusión (estatal) no es apto para dar respuestas válidas a los nuevos dilemas.

Para resolver los dilemas en los que se sustenta, el Estado del Bienestar necesita un cambio radical de los principios teóricos y prácticos a los que debe recurrir. El código relacional parece bastante más adecuado que el de la simple inclusión estatal, también en términos de ventajas evolutivas comparativas. Pedir un nuevo Estado del Bienestar significa pedir que el sistema económico-administrativo se ponga al servicio de las instancias éticas de la sociedad, y ello no puede lograrse mediante un principio de inclusión sistémico carente de ética.

Hasta hoy, estos dilemas se han afrontado de diversos modos, que tomaría demasiado tiempo recordar y tratar en este lugar.

En general, estas modalidades han tendido a separar el sistema de previsión social del Estado y a hacer de él una especie de campo intermedio entre las funciones de decisión política del Estado y la denominada Sociedad del Bienestar (welfare society) o Sociedad solidaria (caring society).

Así, se ha extendido aquella esfera de lo social que algunos - a partir de $\mathrm{H}$. Arendt (1964) — consideran «im-política», o en la cual parece existir «el olvido del político» (Caillé, 1993).

En realidad, esta esfera de lo social, intermedia entre el Estado y la sociedad civil, también es objeto de atenciones e intercambios por parte de la economía de mercado.

En Europa está predominantemente condicionada por el Estado, mientras que en los EUA está predominantemente vinculada al mercado. Tanto en un caso como en otro, Estado y mercado tienden a engullirla.

2 La literatura sobre contratos relacionales es amplia y no puede discutirse en este lugar. En cualquier caso, consultar: Eisenberg (1995); Donati (2001a). 
En todo el Occidente resulta evidente la necesidad, pero al mismo tiempo la dificultad, que la denominada «esfera de lo social» (o de la socialidad en las redes asociativas extrafamiliares) se otorgue una constitución autónoma, se haga sociedad sui generis, se convierta de verdad en un Sector Terciario, simétrico y de igual dignidad respecto a los otros dos (Estado y mercado).

Desde ahora, los tres grandes actores del paso a un nuevo orden societario (es decir, el Estado, el mercado y el sector terciario) se han combinado entre sí de maneras confusas, se han mezclado y han interactuado sin encontrar un ordenamiento social que respete sus diferencias y los integre de forma tal que un sector no colonice al otro.

Si esto ha ocurrido, y sigue ocurriendo, ésta es mi tesis, la causa cabe encontrarla en el hecho de que Estado y mercado han actuado con su principio de inclusión, que no ha tenido en cuenta los principios reguladores diferentes que operan en el sector terciario (privado social) y cuaternario (constituido por las familias y las redes informales). Los sectores terciario y cuaternario han debido allanarse a las lógicas lib/lab de la inclusión y, de este modo, han tenido que renunciar a producir una ética capaz de influir en los grandes procesos societarios. Los dos sectores principales del Bienestar (Estado y mercado), con integraciones supletorias sin ánimo de lucro, siguen adelante cada uno en base a una «moral» propia, que adolece de un fundamento ético común y que, en cualquier caso, poco o nada comunica con la ética del mundo vital.

En consecuencia, resulta difícil decir cómo pueden afrontarse y resolverse los dilemas. Pero es evidente que, hoy, la prioridad vuelve a los mundos de la vida. El Bienestar debe rediseñarse más bien como un problema de diferencias, de mezcla y de sinergias entre los diversos sectores participantes. Deben buscarse nuevos horizontes de pluralismo del Bienestar (welfare pluralism: Fazzi y Messora, a cargo de, 1999). Pero en el marco de la sociología relacional debe hacerse algo más y diferente. Se deben buscar distinciones y criterios de welfare mix que vayan más allá del principio de inclusión practicado como aceptación de los comportamientos más diversos, con la única condición de que no resulten perjudiciales para los otros. Esto es particularmente evidente cuando se asume, como punto privilegiado de observación y de actuación, el sector constituido por las familias, porque es ahí donde se decide el efecto de los otros tres sectores (Estado, mercado, instituciones sin ánimo de lucro) en el bienestar de las personas a través de sus estilos de vida. Y este mundo debe redefinir hoy el Bienestar en clave contraparadójica (Donati, 1999).

Las soluciones que hoy salen a la palestra para responder a los dilemas del Estado del Bienestar se inspiran en tipos de lógica que muy poco responden a las exigencias de una cultura civil del mundo vital. Son, por un lado, la lógica de la integración sistémica y, por 
otro, la de la integración social. En el primer caso se pretende asegurar el Bienestar por vía sistémica, y en el segundo caso, por vía de sociedad civil.

a) El gobierno basado en lógicas sistémicas. Es el heredero de la primacía de lo político y de la primacía funcional del Estado (marxismo e ideologías socialistas varias), que ahora son vistas y funcionan como primacía de la comunicación sistémica. Aquí, el Bienestar se gestiona a través de aparatos impersonales y de organizaciones «automáticas» que buscan inmunizarse de su ambiente humano (es decir, de los comportamientos de las personas, con su subjetividad). Por ello están abiertos a procesos de globalización, entendidos no sólo y no tanto como procesos de creciente interdependencia funcional a escala mundial, sino sobre todo como procesos que alimentan formas estandarizadas de actuación uniforme y/o altamente anónima, incluso en la esfera del bienestar.

b) El gobierno basado en lógicas de integración social. Es el heredero del liberalismo civil, que opera con miras a la liberación y a la emancipación de una nueva sociedad civil, en la cual son los sujetos individuales, con sus grupos y asociaciones, los que construyen el bienestar (caring o friendly society).

En principio, estas dos modalidades son necesariamente opuestas y conflictivas a priori. También pueden resultar complementarias y, en determinados casos, incluso sinérgicas. Pero el hecho es que, hoy, estas dos lógicas no se relacionan entre sí para perseguir los objetivos más positivos de ambas, sino más bien lo contrario. En vez de tener lógicas sistémicas que persiguen el bien común en relación a sujetos libres-y-responsables, prevalecen las lógicas sistémicas que persiguen todos los fines particularistas que cabe imaginar en relación a comportamientos desprovistos al máximo de responsabilidades subjetivas. Las lógicas sistémicas contribuyen a crear una «sociedad civil» específica (que todavía llamamos así, según una expresión moderna que ya no se corresponde con los hechos), la cual descarga sus responsabilidades en máquinas organizativas impersonales de seguridad social. En realidad, deberíamos decir que la sociedad civil se diferencia en una parte sistémica —lo civil de las lógicas globalizantes_ y una parte social —lo civil hecho de integración social—.

El modo en que estas dos lógicas funcionan en la actualidad en los intercambios recíprocos tiene carácter de sinergia perversa. Las lógicas sistémicas no tienden a reforzar los sujetos sociales del mundo vital para que sean más autónomos y responsables, sino que, por el contrario, los privatizan y los enajenan de sí mismos todavía más. Es como si el Bienestar estuviera dividido en dos campos: el «público», dejado a las grandes máquinas anónimas de la seguridad social, éticamente in-diferentes, y el «privado», donde se busca una humanización de los servicios sociales que, aunque no está carente de sensibilidad ética, no se rige por esos nexos significativos entre libertad y responsabilidad de los sujetos, en 
que precisamente consiste la vida sana. Una sociedad civil construida de ese modo, por estar privada de responsabilidades éticas, se convierte en in-civil.

La sinergia perversa entre lógicas sistémicas y lógicas de (des)integración social produce una forma de Estado del Bienestar que, en vez de estimular a las personas y a los grupos sociales a emprender iniciativas para salir de su estado de necesidad (es decir, de las diferentes formas de pobreza, viejas y nuevas), las inmoviliza y contribuye, aunque sea indirectamente, a hacer que prevalezcan procesos de mercantilización de la vida humana, contra los cuales luchan en vano las varias éticas del mundo vital. Un Estado del Bienestar concebido como «institución de reparación moral» (Gehlen, 1994) representa la fuerza y la debilidad de la denominada civilización occidental del capitalismo tardío. De ahí surge la impresión, tan difundida hoy en día, de que nuestra civilización avanza como el Titanic, donde se baila mientras la nave se dirige a chocar contra el iceberg.

Si Occidente pretende salir de sus contradicciones y de la ruta de colisión que lo conduce hacia lo que puede destruirlo (la ruta de la autoaniquilación), debe cambiar de dirección respecto a las lógicas y a las soluciones concretas por las que se sigue moviendo. Pero ¿por qué ruta? A mi parecer, se trata de instaurar lógicas sinérgicas de tipo positivo en las políticas sociales (Donati, 1996).

3.2. El escenario actual, como ya he comentado, está marcado por una mezcla entre vías de integración sistémica y de integración social, que se persiguen en un círculo perverso. La dirección a tomar debería ser la de desmembrar este círculo perverso y producir una diferenciación-integración positiva entre los dos tipos de lógicas. Es decir, tenemos necesidad de un modelo de desarrollo de la vida social en el que las dinámicas sistémicas y las de integración social refuercen entre sí sus mejores cualidades, las prestaciones funcionales y con sentido que cada lógica puede ofrecer, en la dirección de producir relaciones sólidas de carácter solidario e incrementar la capacidad de reciprocidad humana, en lugar de anular, debilitar o distorsionar estas cualidades relacionales.

La solución a este problema la identifico en el paso del código moderno de la inclusión al código trans-moderno de la relacionalidad. El primero lleva a todos a una lógica lib/lab, mientras que el segundo respeta las diferencias legítimas y las pone en relación según normas de subsidiariedad recíproca.

Cabe partir de la realidad efectiva, es decir, del hecho de que se está produciendo una diferenciación tal de la sociedad que diseña un nuevo escenario, que ahora se encuentra ampliamente latente, en el que encontramos cuatro grandes ámbitos del Bienestar, con sus características peculiares: mercado, Estado, ámbito privado social y redes familiares. 
¿Cuáles son las implicaciones de este proceso de diferenciación en las esferas de bienestar en los planos político y ético?

Quisiera destacar algunas de ellas.

i) La política resulta una «función más difusa», que se diferencia en los diversos ámbitos y que ya no es monopolio del Estado. Cada ámbito y cada actor tiene y hace una política social propia.

ii) Del mismo modo, la ética resulta una «función más difusa», que debe otorgar criterios adecuados en cada ámbito específico y que, por tanto, pertenece a una esfera especializada, y en cierto sentido separada, de la sociedad, como antes.

Naturalmente, en este tipo de sociedad, los riesgos de la política y de la ética son todavía mayores que antes, por la posible fragmentación del sistema global, consecuencia del hecho que no existe un Centro o un Vértice de la ética y de la política. Pero este hecho, que es un legado de la modernidad, no puede eliminarse. La creciente contingencia de toda la sociedad puede abordarse y resolverse sólo en la medida en que las personas puedan actuar en esferas concretas y personalizadas, aunque sean limitadas, en donde sea posible tener una "comunidad societaria», es decir, orientaciones de valores comunes con referencia a algo universal, más allá de las lealtades, pertenencias y características personales y particulares de adscripción de los individuos. Por otra parte, precisamente por el carácter «difusivo» de la ética y de la política, deberían proporcionar esa generalización de valores mínimos comunes que es necesaria para la integración de las diversas esferas del Bienestar y de los diferentes segmentos (networks) de sociedad.

3.3. A través de estos procesos de diferenciación está naciendo una nueva cultura del «hacer sociedad», según un código simbólico y normativo de tipo relacional. No cabe ocultar que existe el peligro de que, dentro de dicho código, emerjan procesos degenerativos. Este riesgo, como sabemos, es intrínseco a una sociedad compleja que quiere y debe mantener amplios márgenes de discrecionalidad en los comportamientos personales. Pero el código relacional, en principio, puede poner en práctica condiciones al contorno y reglas que prevengan conflictos y patologías mejor de lo que pueda hacerlo el de la inclusión estatal lib/lab.

La diferencia con el Bienestar moderno se basa fundamentalmente en el hecho de que los principios en los que se inspiran las políticas sociales cambian radicalmente: se pluralizan y no pueden ser reconducidos ad unum mediante su neutralización ética. 
En este orden, el Bienestar ya no es cuestión de asistencia de individuos y categorías sociales abstractas, sino que se convierte en el problema de la autorresponsabilización de asociaciones y redes comunitarias, del pluralismo de actuaciones en red en una caring society que se regula por el patrón de un principio de subsidiariedad postliberal y postsocialista, en el cual el bien común, cuya exigencia justamente se reivindica, se convierte en un bien relacional, realizable a escalas específicas (Donati, 2000a, cap. 2).

Mi opinión es que el Bienestar puede moverse en tal dirección, a condición que esté pensado en el marco de una ciudadanía postmoderna, que ya no absorbe al hombre, sino que traza una línea de distinción clara y renovada entre hombre y el ciudadano. Expreso este cambio con la fórmula: pasar de la ciudadanía lib/lab a una ciudadanía compleja, que es una combinación inteligente de ciudadanía estatal y ciudadanía societaria. En la ciudadanía societaria se puede hacer sociedad de diversos modos y a escalas (territoriales y comunicativas) bastante diferenciadas, en las cuales, con todo, el hombre debe seguir siendo siempre entorno y patrón del ciudadano. Este paso, ciertamente, se presenta bastante problemático. Pero, en cualquier caso, hoy parece ser vía obligatoria.

En las sociedades postindustriales o complejas, las políticas sociales se rediseñan según un modelo societario en el cual el Estado actúa de ordenador general de un sistema autorregulado en todo lo posible. Se adopta un enfoque que, en sentido amplio, puede denominarse de «guía relacional», según el cual la sociedad se autorregula a través del máximo posible de autonomías sociales, que de forma cooperativa conciertan las normas en base a las que adoptar las decisiones vinculantes para todos. Vuelve a escena el principio mutualista, pero con otro significado muy distinto y con otras estructuras y funciones respecto a las sociedades de «mutuo socorro» del siglo XIX. La mutualidad: a) queda desligada de la división social del trabajo, ya que debe corresponder a otras necesidades sociales, y b) se gestiona a través de una pluralidad de actores, en combinaciones en las que pueden jugar un papel, además de los sujetos de la mutualidad, el Estado (entes públicos o semipúblicos), agencias de mercado y redes informales. De este modo, la gestión de las desviaciones y patologías ya no es una cuestión de compensación de las desventajas por medio de más inclusiones ulteriores de los comportamientos variables (reducción del daño), sino que se convierte en un objetivo de prevención del riesgo mediante la afirmación de una normalidad entendida como adecuación relacional a las necesidades sociales en contextos determinados.

3.4. Hoy hay quien todavía cree que el conjunto de los derechos de los ciudadanos puede garantizarse sólo si el mercado (entendido como noción sociológica generalizada, incluso en los estilos de vida) es conducido a normas de funcionamiento que, por una parte, recuperen eficiencia y capacidad productiva y, por otra, pongan a disposición más recursos 
para la inclusión política de las fracciones débiles de población. Pero la fórmula «más ciudadanía mediante más mercado», o bien «más ciudadanía mediante un mercado más eficiente», resulta equívoca y restrictiva. Perpetúa la idea de que la ciudadanía es una cuestión de canje (trade-off) entre el Estado y el mercado, y limita los contenidos de la ciudadanía a dicho intercambio. Por el contrario, la sociedad postindustrial no puede leerse como una continuidad de la anterior: presenta enormes cesuras y discontinuidades. En particular, en los siguientes aspectos:

a) La ciudadanía postindustrial resulta un diseño global que debe distinguir las diferentes esferas (sociales, económicas, políticas, culturales), sin que se separen o se confundan, y luego encontrando normas apropiadas en y para cada una de ellas. El sentido y la metodología de los derechos de la ciudadanía no son los mismos si esta última es observada en el sistema económico, en el político, en el social o incluso en el cultural. El referente ya no es el trabajador, sino el hombre, la persona humana concreta. La nueva ciudadanía tiene su referente simbólico no en la pobreza o en los riesgos del industrialismo, sino en la cultura impulsora, en la del terciario y del «cuaternario», centrada en la calidad de vida y en los problemas de sostenibilidad de los estilos de vida más diversos.

b) Las políticas sociales ya no se encuentran en el binomio Estado-mercado, sino que proceden de una dinamicidad propia y diferenciada de las otras esferas, fuera del mercado y del Estado, con actores, procesos e instituciones propios. Son estas subjetividades las que redefinen las necesidades (como intereses) y los derechos (como identidad), y es aquí donde se genera el encuentro con el complejo «político-económico». La variable ecológica impone una nueva reflexión acerca del impacto de las políticas sociales en el ambiente demográfico, social, económico, político, así como en el ecosistema físico. Implica nuevas fronteras allí donde la política social ya no es cuestión de redistribución de los recursos producidos por el mercado, sino conflicto de intereses entre productores y usufructuarios del entorno, así como entre identidades socioculturales diversas.

En este escenario, profundamente transformado, se requieren nuevas bases estructurales, funcionales y morales de la ciudadanía, sin las cuales las políticas de control social no pueden llevarse adelante.

Estas bases morales, funcionales y estructurales de la ciudadanía hacen referencia al código simbólico que ya no opera en base a la distinción incluido/excluido del sistema político estatal (como es propio de los sistemas políticos modernos: Luhmann, 1970), sino en base a la distinción relacional/no-relacional, es decir, si los sujetos en cuestión mantienen o no relaciones válidas y significativas bien dentro de sus formaciones sociales o bien en sus relaciones con otras formaciones sociales relevantes a efectos de bienestar. 
La lógica de la inclusión lib/lab razona así: si desarrollamos la economía (el mercado, el bienestar de los consumos), lo social debe ir al mismo ritmo; el desarrollo económico debe ir seguido de una justa redistribución.

En cambio, la lógica de la inclusión relacional razona del siguiente modo: es preciso perseguir un desarrollo que no carezca de motivación social, es decir, que incorpore lo social ex ante, porque es mejor renunciar a ciertas ventajas económicas si éstas deben quedar anuladas por la implosión de lo social (habida cuenta que dicho resultado conlleva nuevas exclusiones sociales, además de producir deseconomías externas).

El lib/lab dice: demos libertad económica y luego redistribuyamos la riqueza; demos libertad y luego controlemos; que lo económico produzca bienes y servicios y, luego, generemos la cohesión social necesaria para controlar los efectos negativos de lo económico.

En cambio, el código relacional dice: la libertad económica debe ir orientada desde el principio hacia el sentido social; la libertad y el control son constitutivos uno del otro; no al desarrollo económico sin desarrollo social; generemos más cohesión social mediante la sinergia entre lo económico (=medios técnicos) y lo social (=reglas humanas de intercambio social). La idea es que el societarismo es el producto del efecto de reciprocidad (Wechselwirkung) entre lo económico y lo social, más bien que una combinación ex post de los opuestos. El Bienestar va vinculado a un contrato civil que tiene lugar antes de poner en relación lo económico y lo social. No esperamos a que el bienestar sea el resultado de un ajuste entre lo que ha producido lo económico y la acción de entitlements que se encargan de redistribuir los beneficios a los excluidos.

La lógica lib/lab, queriendo o sin querer, afirma que primero lo económico modifique lo social liberando las libertades de mercado (lib) (con la consecuencia de desgarrar el tejido relacional que define la condición inicial) y luego se encargue de compensar los déficits de bienestar que de ello se deriven mediante controles de inclusión en determinadas garantías, forzosamente limitadas (lab). Esta lógica se aplica a todas las formas de vida, a los estilos elegidos por los individuos y, por tanto, también una lógica de tratamiento de la pobreza y de las patologías sociales.

En cambio, la lógica societaria afirma que el bienestar es el producto de sujetos que se orientan a los otros según principios de un relacionamiento justo, porque el bienestar que debe producirse es, en sí mismo, un bien relacional (véanse, por ejemplo, los contratos relacionales, entendidos como contratos a largo plazo que no confieren una primacía de vaIor a la mera eficiencia económica y técnica, aun disponiendo de sistemas exhaustivos de rendición de cuentas, sino que privilegian la relación social entre productores y consumido- 
res). Esta misma lógica es válida para cuanto concierne al tratamiento de los estilos de vida y, por tanto, a la prevención y a la resolución de las patologías y desviaciones sociales.

Contrariamente a la típica lógica moderna de la inclusión, que lo reconduce todo — directa o indirectamente, implícita o explícitamente, a corto o a largo plazo- al sistema políticoadministrativo, la lógica relacional o societaria reconduce la exclusión, la patología o la desviación social al modo de ser y de actuar propio de cada esfera social, e interviene para relacionar entre sí las diversas esferas de actuación en base a principios de subsidiariedad recíproca, a fin de revalorizar las responsabilidades en las libertades de los sujetos.

\section{CONCLUSIONES: CÓMO DEBEMOS INVENTAR EL NUEVO BIENESTAR («DE CUARTA GENERACIÓN»), O LA HIPÓTESIS DEL «ESTADO SOCIAL RELACIONAL»}

4.1. Estamos obligados a pasar a una nueva fase histórica y, por tanto, a concebir un "cuarto modelo de Estado del Bienestar», un Estado social de cuarta generación, después del paternalista, el asistencial y el intervencionista.

Un poco por toda Europa, buena parte de los teóricos de la política social y del Bienestar han suscitado, sobre todo, dificultades, temores y dudas a propósito de la desestatalización del sistema del bienestar, más que expresar proyectos alternativos (véanse, por ejemplo, Taylor-Gooby, 1989; Jones, 1993; Dahrendorf, 1994). Una gran parte de las propuestas insisten en los viejos esquemas, recurren a modelos superados y, por tanto, son de escasa ayuda.

La propia Unión Europea no ha ido mucho más lejos. En una serie de Informes y Recomendaciones emanados durante los años noventa, se ha limitado a manifestar la exigencia de una modernización de los sistemas de la seguridad social que, por un lado, mantenga el gasto bajo control y, por otro, asegure los estándares mínimos ${ }^{3}$. Aunque la UE reivindica justamente los méritos de un sistema de protección social típico de los países que la componen, por distinción frente a las grandes regiones del mundo (en particular, los Estados Unidos y los países asiáticos), aun así no queda en absoluto claro cómo puede mantener-

\footnotetext{
3 Desde julio de 1992, la Comisión de la UE ha adoptado Recomendaciones que establecen una serie de fines comunes de política social, expresados en algunas líneas rectoras para la convergencia hacia objetivos de lucha contra la exclusión social. En base a ellas, se requiere a los Estados miembros: a) que garanticen a todas las personas de la Comunidad un nivel mínimo de recursos acorde con la dignidad humana y el acceso a los servicios sanitarios; b) que promuevan la integración social de todas las personas con residencia legal en el territorio de los Estados miembros y que favorezcan su acceso al mercado de trabajo; c) que proporcionen una renta a los trabajadores que cesan en su actividad laboral por motivo de edad o que se ven obligados a dejarla por determinados riesgos normativizados.
} 
se dicho modelo ante los procesos de globalización de la economía con la actual creciente movilidad laboral y de capitales, y los previsibles incrementos en los procesos migratorios.

A fecha de hoy, buena parte del debate discurre entre defensores y desmanteladores del Estado del Bienestar. Expresado en estos términos, el debate casi siempre termina en un enfrentamiento estéril que, al final, se desvía del tema, ya que conduce hacia derivaciones históricas, bien en la repropuesta de modelos asistencialistas superados, bien en la línea de una privatización más o menos desregulada. No me detendré más en este punto, que ya ha sido discutido en muchos otros lugares.

Lo que conviene, más bien, es ir al busilis del problema: ¿cómo podemos delinear el Estado del Bienestar de cuarta generación?

Mi propuesta es recabar el mayor número de hipótesis sobre el tema en dos paradigmas y concebir el Estado del Bienestar de cuarta generación como respuesta a sus ventajas y desventajas comparativas. Los dos paradigmas son: el modelo lib/lab (basado en un fuerte control público, pero relanzado en una nueva versión de promoción de las libertades privadas) y el modelo societario del bienestar plural (basado en la producción de bienestar mediante la diferenciación social de autonomías sociales integradas según el principio de ciudadanía societaria). Examinémoslos de forma analítica para luego confrontarlos.

I) El modelo neo-lib/lab, de forma resumida, sostiene la idea de un Estado social que haga compatible el máximo de libertades individuales con el mínimo de bienestar garantizado colectivamente a todos. Su objetivo consiste en expandir la seguridad social asegurada por vía estatal (componente o aspecto lab) a fin de conseguir un mayor nivel de vida con una mayor libertad privada (componente o aspecto lib). La idea rectora que los inspira es la de asegurar una red de seguridad mínima (safety net, en el estricto sentido de protección social) a todos los ciudadanos, dejando que, una vez asegurado ese mínimo, cada uno busque la manera de perseguir y de asegurarse «de forma privada» todo el bienestar que le sea posible ${ }^{4}$.

Se discute si el mínimo garantizado debe ser universalista e incondicional o destinado a ciertos grupos — denominados grupos objetivo (target)—e incondicional. Muchos son los teóricos a favor de la primera solución (Rothstein, 1998). Pero, de hecho, todos los gobiernos actuales en Europa (sean de centro-izquierda o de centro-derecha) están eligiendo la segunda vía.

\footnotetext{
4 El modelo busca compaginar la primacía de la libertad (dice R. Dahrendorf: «freedom above all»), según la formulación del liberalismo clásico (ver Weale, 1983), con el criterio rawlsiano de la justicia en términos de maximin (Rawls, 1982) y una buena dosis de pragmatismo sobre la mejor combinación de las agencias para el bienestar (welfare mix). Entre los primeros, se encuentra claramente formulado por Ken Judge (1987: pp. 1-43).
} 
Paradigmático resulta el caso de Holanda, en donde se busca realizar un programa de seguridad social que garantice un umbral mínimo de acceso igualitario (equality threshold), el cual, no obstante, está condicionado al hecho de demostrar compromiso por la máxima participación en el mundo productivo. El eslogan es: «participa o húndete» (Van der Veen, 1998).

La nueva versión lib/lab, de manera continuista con el pasado pero contraria a las soluciones anteriores más estáticas, enfatiza la sinergia dinámica entre lo público y lo privado, en la dirección de hacer crecer el lado público (estatal) en función del servicio que presta el máximo bienestar individual privado.

La limitación del principio de inclusión (y, en ocasiones, su inversión, es decir, la exclusión de los beneficios) tiene lugar adoptando estrategias de política social basadas en el cálculo de los riesgos que conducen a situaciones de necesidad, y distinguiendo entre riesgos forzosos (que los individuos deben afrontar involuntariamente) y riesgos asumidos voluntariamente (que, por tanto, producen estados de necesidad previsibles, como las conductas de fumar, de consumir drogas, etc.).

Ésta es la vía en la que hoy día las coaliciones socialistas y liberales consiguen encontrar puntos comunes de encuentro.

En este paradigma puede verse una ulterior emancipación de las libertades individuales. El llamado «neoindividualismo institucionalizado» celebra aquí sus mayores éxitos. Pero es evidente que el bienestar privado que se genera, colectivamente garantizado a quien lo merece porque no se sustrae a los imperativos del mercado capitalista, vive en vacíos relacionales de sentido y en una intrínseca fragilidad que, muy a menudo, resultan fatales. De ahí el continuo impulso de la intervención pública, que es como el perro que se muerde la cola, dado que es la causa de los problemas que quisiera resolver. De todos modos, tiene su fuerza, basada en el hecho de que combina tres elementos fuertemente adquisitivos: a) la responsabilidad individual (con el énfasis de la noción de mérito y la distinción entre quien merece ser ayudado y quien no); b) un interés directamente productivista (lograr que cada cual trabaje lo más posible); c) la idea de que la ocupación profesional es la contribución más significativa que una persona puede (y debe) aportar a la sociedad. Tales principios se justifican con la idea de que, en contrapartida, se puede sostener a los individuos «verdaderamente débiles y necesitados». La máxima de estas políticas es «rigor, seriedad y mérito». Se distingue entre pobres que merecen y pobres que no merecen, según una visión de vago regusto neocalvinista. Tras estos cambios hace su aparición una nueva visión de los derechos sociales, menos solidaria y menos universalista, aunque más dialogante y discursiva (Cox, 1998). 
II) El modelo societario del bienestar plural contempla el Estado social desde otra óptica. La idea rectora no es la de liberar a los individuos como tales, asegurándoles que no caerán bajo las redes de la protección mínima (safety net), siempre que lo merezcan a los ojos del político decisorio, sino la de mantener una diferenciación positiva entre actos y principios varios que persiguen el bienestar, mediante la promoción de autonomías sociales y una articulación solidaria entre ellas (ver Evers y Olk, 1996, y el esquema 2 de Donati, 2002).

Aquí hay constancia de que existen sectores varios que producen bienestar según una pluralidad de principios, todos ellos reconocidos y consolidados en su especificidad funcional. Fundamentalmente, se trata de cuatro sectores: el estatal, el comercial, el privado social y el familiar-informal. Es decir, bienestar a través del dominio sobre los recursos, a través de la competencia, mediante asociación voluntaria, o bien a través de la obligación personal, así como sus posibles sinergias ${ }^{5}$. Los actores colectivos (Administración Pública, empresas privadas, asociaciones del sector privado social, grupos de familias) son puestos en red como nodos comunicativamente simétricos, incluso funcionalmente diferenciados. Ello significa que tienen funciones diversas, más o menos importantes, pero que no existe jerarquía comunicativa alguna entre ellos. La titularidad del solicitante debe respetar el ámbito específico de bienestar de que se trata (es decir, los derechos sociales de los solicitantes se diferencian en base al tipo de bienestar que está en juego y al sujeto de referencia que se hace cargo de ellos: derechos sociales de ciudadanía, derechos del consumidor o cliente, derechos de asociación, derechos comunitarios). Cada sector tiene sus propias reglas de acceso, sus propios medios de intercambio, un valor central de entrada, criterios para valorar el bien añadido, y además hace frente a diferentes déficits en las situaciones concretas de malestar.

La estrategia para afrontar los riesgos no recurre únicamente a las responsabilidades individuales (directas o indirectas), sino que tiene en cuenta el hecho de que los riesgos son una construcción social que depende de la estructura (reglas) de los sistemas sociales de intercambio (incluidos los contratos).

Es ésta la organización de la sociedad concebida según el que denomino principio de la ciudadanía societaria (Donati, 2000a). Cabe señalar que, en tal configuración, la diferenciación es más bien funcional (porque cada sector tiene sus funciones específicas), pero, en conjunto, tiende a ser superfuncional, por cuanto se propone afrontar un número indefinido de necesidades de bienestar mediante la iniciativa y el papel activo de una pluralidad de sujetos no necesariamente dirigidos por el poder político. Como tal, no encuentra los lí-

5 Como es el caso de las fundaciones sociales, y en particular de las fundaciones comunitarias (community foundations): ver Casadei (1997). 
mites que, periódicamente, debe afrontar el modelo lib/lab, cuando las reglamentaciones políticas se vuelven obsoletas o encuentran barreras insuperables, o deben hacer frente a efectos perversos inesperados. De hecho, puede hacer frente a estas emergencias o disfunciones mediante una negociación más libre, solidaria y reticular, entre los diversos sectores que generan bienestar.

En este orden, el Estado social se transforma en una de las varias formas reguladoras del Bienestar (bienestar estatal), mientras se fomentan los demás sectores, con sus reglas, favoreciendo así el papel de la sociedad civil como productora de bienestar civil. Es evidente que, dentro de este marco, la desregulación estatal no debe entenderse como privatización dejada al mercado (por ejemplo, como re-mercantilización del trabajo), sino como un fomento de nuevas redes de intercambio entre los actores civiles del bienestar (mercado legal, sector de instituciones sin ánimo de lucro y redes familiares, con sus formas asociativas organizadas). Por tanto, el área del bienestar civil no debe entenderse como un campo privado desresponsabilizado frente a la cosa pública, sino como una nueva esfera pública que posee precisas funciones positivas para el bienestar individual, colectivo y comunitario ${ }^{6}$.

Existen experimentos en marcha en esta dirección, sobre todo en los países en los que el modelo lib/lab, al estar más avanzado, puede generar nuevas modalidades de hacer sociedad civil a través de sujetos sociales que piensan y gestionan los problemas de bienestar fuera del viejo modelo social-democrático. Empíricamente, se localizan en las regiones del centro y norte de Europa, a menudo como modelo a latere del modelo lib/lab, que subsiste como modelo estructural-institucional.

Los problemas de este segundo modelo radican en las dificultades de coordinar los diferentes sectores, es decir, en la forma en que puede concebirse y organizarse la red de las redes sociales. Se trata de construir redes que consigan equilibrar diferenciaciones e integraciones, y que por tanto sean capaces de generar cohesión social en el marco de libertad de las iniciativas. Pero no podemos detenernos sobre ello en este lugar.

4.2. Las dos vías neo-lib/lab del bienestar societario (plural y solidario) tienen algo en común y algo que las distingue claramente.

a) Las convergencias residen en el hecho que ambos modelos rechazan el aumento de tamaño del Estado. Si bien con matices diferentes, rechazan que el nuevo Bienestar deba

6 Dicha esfera pública debe entenderse como «el conjunto de las instituciones cuyos miembros están fundamentalmente comprometidos en una serie de actividades no-estatales — producción económica y cultural, vida familiar, asociaciones voluntarias-, y de este modo preservan y transforman su identidad con el ejercicio de todo tipo de presiones o controles sobre las instituciones del Estado» (ver Keane, 1988, p. 14). 
organizarse en torno a la idea de que una sociedad debe producir su bienestar teniendo en el Estado un sistema ordenador general que sirve (que es de servicio) para emanar reglas mínimas y fundamentales, reduciendo la gestión estatal de las instituciones de bienestar a lo que no puede ser desarrollado por otras agencias.

Los modelos lib/lab y los societarios deben comprenderse como una evolución de los Estados del Bienestar europeos y, por tanto, diferentes y distantes no sólo de los «modelos orientales» (incluidos los comunistas), sino también del modelo estadounidense (prototipo de los liberal-residuales), al que con justicia se le considera «en la edad de piedra», aun siendo los EUA una sociedad económicamente rica (Anspach, 1996). Los modelos lib/lab y societarios, así como están de acuerdo en oponerse a la idea de un Estado social totalmente planificado, convergen en la idea de un Estado social mínimo o residual. El Estado social europeo se distingue por mantener firme la idea de que el poder político no sólo hace las reglas y las hace respetar, sino que también debe perseguir objetivos fundamentales de justicia social. No se acepta la idea de que el Estado sea mínimo, si por mínimo se entiende -como hacen los neoliberales - que debería limitarse a actuar de árbitro entre las partes, dedicándose simplemente a respetar las reglas de un juego en el que cada uno arriesga como y cuanto quiere. Por tal motivo, tampoco puede ser residual porque, en tal caso, llegaría siempre ex post factum y debería interesarse única y exclusivamente en los excluidos (los más débiles y marginados). En cambio, debe concentrarse en funciones legislativas (de dirección) y de gobierno, dejando la gestión, cuando ello es posible, a otros actores y procurando que los controles no resulten opresivos, sino en lo posible orientados a revalorizar las capacidades de autogestión y de autorresponsabilización de los sujetos promotores del bienestar.

b) Pero las dos vías también se diferencian claramente entre sí. ¿En qué?

Las divergencias se refieren al sentido (formas y contenidos) de la regulación social en su conjunto. En cuanto a los tres indicadores sociológicos fundamentales (es decir, el sentido del Estado como ordenador general, las reglas mínimas garantizadas por el Estado y el criterio rector de la política social), podemos decir lo siguiente.

En el modelo lib/lab:

- El Estado es entendido como ordenador general, ya que mantiene el papel de gran supervisor que utiliza el sistema político-administrativo para controlar todos los intercambios que este último efectúa con la sociedad civil; esta vía todavía confía al Estado del Bienestar la misión de dirigir (con dirección y coordinación) todas las transacciones sociales, en función de ciertas libertades privadas seleccionadas; es el Estado que sigue produciendo 
—indirectamente, ya que no la gestiona directamente— «su» sociedad civil, porque define qué cosas se dejan o se imponen a los particulares y qué cosas no.

- Las reglas mínimas (a las cuales nadie puede sustraerse) respecto de las cuales el Estado sale garante son las que definen los límites de las iniciativas privadas y del poder público, a fin de mantener el control político sobre las transacciones sociales, preservando así, e incluso acentuando, la distinción entre esfera privada y esfera pública, que ulteriormente se distancian entre sí, incluso cuando se utiliza y favorece la combinación de ambas.

- El criterio rector que inspira la política social es el denominado individualismo institucionalizado (no cierto individualismo salvaje), o neoindividualismo democrático, que tiene como objetivo crear un escenario de oportunidades para las elecciones individuales y, por tanto, está encaminado a maximizar el bienestar individual en la esfera privada, con la única limitación de no dañar el de los demás; queda excluida cualquier política de vinculación social si con ella se pretende perseguir ex ante objetivos y criterios de relacionamiento solidario entre los individuos (la solidaridad puede ser un resultado esperado, pero no un criterio de elección normativa a priori).

En cambio, en el modelo del bienestar societario, basado en la diferenciación plural y solidaria:

- El Estado es ordenador general, no por el hecho de utilizar el poder político-administrativo para regular todas las transacciones sociales, sino porque, mientras promueve las formas autónomas de producción y de asignación propias de cada esfera, se preocupa de verificar la compatibilidad entre las acciones de los diversos sectores y sus resultados, al objeto de asegurar que el bienestar social que se genera y distribuye a los diversos grupos de población crece y no disminuye en sentido absoluto ni en sentido relativo.

- Las reglas mínimas que el Estado garantiza conciernen a los nexos que vinculan intrínsecamente entre sí las libertades y las responsabilidades de cada sujeto, así como las aportaciones que cada sujeto efectúa a la comunidad y los beneficios que recibe de ella; en resumen, se propone garantizar la equidad de los contratos en un contexto de reglas de carácter comunitario más bien que individualista.

- El criterio rector de la política social consiste en buscar el relacionamiento más sinérgico posible entre los individuos y los grupos sociales, así como las medidas concretas que lo hagan realidad; por tanto, se persiguen las políticas de las vinculaciones sociales y de los derechos relacionales, favoreciendo las solidaridades primarias y asociativas intermedias entre individuo y Estado. 
La comparación puede desarrollarse de manera más analítica sobre los principios y las articulaciones de los actores que conllevan estas dos vías.

4.3. A nivel de principios, ambos paradigmas (lib/lab y societario) reniegan de las exaltaciones ideológicas del siglo xx y, en cierta forma, convergen en algunos valores-guía comunes, que en cualquier caso interpretan de manera diferente y, sobre todo, buscan realizarse a través de formas sociales básicamente diferentes. Veamos los tres principios más importantes.

i) La subsidiariedad. Es un principio reconocido y perseguido por ambas vías. Pero el lib/lab lo interpreta, sobre todo, en sentido territorial, como defensa de las comunidades menores respecto a las posibles invasiones de las mayores (como, por otro lado, expone el art. 2/b del Tratado de Maastricht, ahora incluido en el Tratado Constitucional europeo), y, por tanto, se limita a recomendar que las decisiones se tomen al nivel más próximo al interesado. El lib/lab interpreta este principio como máximo descentramiento de las funciones estatales del centro a la periferia. Por el contrario, la vía societaria interpreta la subsidiariedad no sólo en sentido territorial y defensivo, sino también como un principio organizativo general (no sólo territorial) y como principio fomentador de las autonomías propiamente sociales (no sólo de los entes estatales locales); y lo interpreta además no sólo en sentido vertical entre instituciones del Estado, sino también en sentido horizontal, es decir, entre las instituciones del Estado y las de la sociedad civil. En este caso, subsidiariedad no significa ni descentramiento ni dejar que cada cual encuentre sus soluciones particularistas, sino preocuparse de que cada sujeto pueda disponer de los recursos necesarios para vivir su autonomía como función social (Donati, 2000a, cap. 7).

ii) La solidaridad. Todos hablan de solidaridad, pero las dos vías son muy diferentes en el modo de entenderla y practicarla. Para el lib/lab, solidaridad quiere decir, sobre todo, recurrir a la redistribución, en la gestión de la relación centro-periferia, donde quiera que esté colocado el centro. En cambio, para la vía societaria, solidaridad significa, sobre todo, favorecer intercambios de reciprocidad entre sujetos que, a diferentes niveles micro, medio y macro, se relacionan entre sí de forma cooperativa, dentro de una articulación compleja. El caso de las intervenciones para sostener lo privado social y la ocupación son dos ejemplos emblemáticos.

iii) La personalización del bienestar. Orientar las medidas de bienestar a la situación concreta de las personas, cuidando de sus exigencias humanas de particularidad más bien que intervenir de modo uniformizante e impersonal, es también un objetivo ampliamente compartido. Pero el lib/lab lo entiende como individualización de las intervenciones (favore- 
cer la libertad del individuo qua talis), mientras que la vía societaria lo entiende como adecuación de las intervenciones a la situación relacional, es decir, al individuo-en-relación. El caso de la renta mínima (llamada también mínimo vital o renta mínima de ciudadanía o de inserción) es muy ejemplificador, ya que la vía societaria subraya el papel promocional de tal medida, más bien que asistencial, como lo hace el neo-lib/lab. Se trata de ver si los denominados «paquetes sociales» tienen en cuenta o no la trama relacional en que se insertan las necesidades individuales, y si las medidas emprendidas favorecen o no la autonomía de tales redes.

4.4. También a nivel de los actores y de las instituciones para el bienestar se percibe entre los dos modelos una cierta convergencia de las referencias operativas. A pesar de ello, subsisten, e incluso se acentúan, diferencias cruciales referidas al modo en que los actores se legitiman y se regulan en sus transacciones e identidades recíprocas (pluralismo, intercambios y autogobierno).

En lo concerniente al pluralismo de las instituciones, que es un valor compartido, se percibe una marcada diferencia entre la vía neo-lib/lab, que recurre sobre todo al pluralismo en las propias instituciones sociales público-estatales, y la vía societaria, que en contraste propone el pluralismo entre las instituciones, sin dar a ninguna de ellas prioridad de principio sobre las otras. A diferencia de la vía neo-lib/lab, que mantiene la primacía de la regulación pública (en sentido estatal), en la vía societaria está la búsqueda de un «espacio público nuevo» en el que también se reconozca — si bien con ciertas condiciones- la función pública de las instituciones no estatales, sin absorberlas en el Estado.

En lo relativo a los intercambios relacionales entre los diversos actores, ambas vías acentúan la búsqueda de nuevas formas de contractualidad. Pero su lógica es bastante diferente. La vía neo-lib/lab mantiene el predominio del Estado, aunque con notables innovaciones (como cuando Tony Blair propone ofrecer un crédito fiscal al empresario que asume a un desocupado en lugar de pagar el subsidio de desempleo al desocupado, a fin de incentivar realmente la ocupación). En cambio, la vía societaria exalta la contractualidad directa entre los sujetos que se intercambian bienes y servicios sociales (en las redes autoorganizadas y, sobre todo, en la economía social). En el futuro, resultará crucial el análisis de los diferentes impactos cuantitativo-cualitativos de estos dos modos de entender los intercambios de entradas-resultados entre los diferentes sectores del bienestar.

Ambas vías se declaran a favor de nuevas reglas de autogobierno que favorezcan la promoción de utilidades colectivas. Pero la vía neo-lib/lab sigue funcionando en buena medida en el marco de un régimen de concesiones en el cual es el Estado el que con- 
cede funciones y ámbitos de actuación. En cambio, la vía societaria propone un régimen normativo de autorregulación de las autonomías sociales, en virtud del cual los sujetos no reciben su autonomía de concesiones del Estado, sino que operan en base a sus propios estatutos, los cuales, lógicamente, deben respetar determinadas reglas comunes.

El caso de las políticas para la familia, que por otra parte está fuertemente ligado a las de lo privado social, resulta emblemático (Donati, 2003). Actualmente, nadie niega la importancia de las familias en la producción de servicios sociales, como ha ocurrido en tiempos de máxima expansión del modelo lab intervencionista. Pero la forma de entender la política para la familia sigue marcada por vertientes bien diferenciadas. Mientras que en la neo-lib/lab sigue siendo decididamente asistencial, la vía societaria, en cambio, se configura como promoción de la familia cual verdadero y auténtico sujeto social. La vertiente neo-lib/lab sigue pensando la política familiar como un aligeramiento de las responsabilidades familiares, o como «compensaciones» o «descuentos» frente a tales responsabilidades. Véanse las medidas más habituales: pequeñas ventajas para los préstamos contratados por las jóvenes parejas que se compran una casa, permisos laborales a los padres en caso de enfermedades graves de los hijos o de los parientes próximos, posibilidad de deducción fiscal de los gastos de canguro (baby sitter) cuando ambos padres trabajan. En cambio, la vía societaria apunta a reforzar la capacidad de autonomía de la familia en sus funciones sociales y, por tanto, a conseguir un sujeto tributario a efectos de equidad fiscal, un sujeto titular de derechos — como el de la educación de los hijos-, un ámbito de relaciones de cuidados que tengan sus propios derechos y deberes, que no deban ser penalizados o castigados sin más, como sigue ocurriendo todavía, sino recompensados, e incluso premiados, en su propia forma de ser (por ejemplo, por el reconocimiento del trabajo en el hogar, de la asistencia a personas de la tercera edad, etc.). La figura 2 ilustra algunos ejemplos de políticas familiares lib/lab y de políticas familiares societarias. 
FIGURA 2

\section{Algunos ejemplos de dos modos de entender las intervenciones y los servicios para la familia a nivel local}

Tipos de políticas

\begin{tabular}{lll}
\cline { 2 - 3 } Tipos de servicios & \multicolumn{1}{c}{$\begin{array}{c}\text { Políticas lib/lab } \\
\text { (basadas en la relación sistema/indivi- } \\
\text { duos en el binomio Estado/Mercado) }\end{array}$} & $\begin{array}{c}\text { Políticas societarias } \\
\text { (basadas en organizaciones autónomas y } \\
\text { simétricas respecto al binomio Estado/ Mercado) }\end{array}$ \\
\hline Consultorio familiar & $\begin{array}{l}\text { Servicio de poliambulatorio gestionado } \\
\text { por el Estado, sobre todo para los pro- } \\
\text { blemas de la mujer (adaptación al mer- } \\
\text { cado y controles estatales). }\end{array}$ & $\begin{array}{l}\text { Ses asociadas para todo el espectro de las dificul- } \\
\text { telacionales en la familia. }\end{array}$ \\
\hline
\end{tabular}

Servicios de asisten- Lista de direcciones facilitadas por ofici- Organización de una red de canguros (baby sitcia infantil e informa- nas públicas a las familias. ción familiar ter) por parte de asociaciones familiares especializadas.

\begin{tabular}{lll}
\hline Renta mínima & $\begin{array}{l}\text { Prestación económica condicionada a un } \\
\text { programa de inserción (RMI) para quien }\end{array}$ & Tasa negativa sobre la renta familiar (NIT) para el \\
& $\begin{array}{l}\text { es indigente, gestionado caso por caso, la unidad familiar (vía fiscal), gestionada a nivel } \\
\text { a través de un contrato entre el individuo }\end{array}$ & local. \\
& y el ente local. & \\
\hline $\begin{array}{l}\text { El servicio de guarde- } \\
\text { ría }\end{array}$ & Guarderías creadas y gestionadas por el & Guarderías en familia, educadoras familiares, pro- \\
& Estado como ayuda al tiempo de trabajo & gramas del tipo «un año en familia», bono a la fa- \\
de madres y padres. & milia para gastar en servicios organizados por las \\
& & propias familias, Tagesmütter (madre de día - mu- \\
& jer cualificada que cuida en su propio hogar a ni- \\
& ños durante la jornada laboral de los padres).
\end{tabular}

Promoción de grupos Un ente local presta ayudas asistenciafamiliares de autoayu- les a petición de los grupos de este tipo da y ayuda mutua para actividades específicas.

Centros para las fami- Un ente local crea y gestiona un centro lias para las familias, a fin de ofrecer servicios particulares a las familias con necesidades y problemas.

Permisos para ma- Normas legales para permitir a los padres y padres dres que se ausenten del trabajo a fin de atender a sus hijos pequeños.
Un ente local adopta medidas universalistas para favorecer la constitución y promoción de grupos de autoayuda y ayuda mutua, con ventajas sin incondiciones que les permitan llegar a ser autónomos.

Constitución de una fundación de comunidad, con socios mayoritarios de sociedad civil, para la promoción de organizaciones de servicios con base familiar.

Contratos relacionales entre las familias y las empresas, en los que se contemplen permisos laborales para un amplio espectro de necesidades familiares (servicio de cuidados a los niños, a los ancianos, a los discapacitados, etc.) garantizados por un fondo público o asociativo.

Préstamos sobre el El ente local presta ayuda financiera a honor los individuos (en el pago de intereses y plazos en la devolución del préstamo) para necesidades concretas (alquiler de la casa, compra del automóvil o de un electrodoméstico, etc.) únicamente en base a la franja de renta del núcleo de población en que vive.
Constitución de un banco ético para préstamos a las familias (hasta rentas familiares medias y considerando el conjunto de las necesidades que afectan a toda la familia) (al igual que con las fundaciones de comunidad, el ente local puede participar como socio de la banca ética, si bien es preciso que exista una mayoría de socios «familiares»). 
4.5. ¿Qué significa todo esto a nivel de los grandes sectores de la protección social?

Las consecuencias diferenciadoras resultan evidentes.

En el ámbito de la previsión y la seguridad social, la vía neo lib/lab mantiene la primacía de las instituciones público-estatales y confía a los particulares un quid de libertades de previsión añadidas y vinculadas (véase el caso de los fondos para pensiones de integración), mientras que la vía societaria persigue una gama más amplia de elecciones de libertad-yresponsabilidad (individual y, sobre todo, solidaria) en los regímenes de seguridad y previsión.

Esto mismo ocurre con la sanidad y la asistencia social. En estos sectores, en donde lo privado social desempeña un papel decisivo y creciente, las dos vías se diferencian claramente, ya que la vía neo-lib/lab otorga un papel residual a lo privado social, mientras que la vía societaria hace de él un pilar autónomo, de igual dignidad y simétrico, si bien con un funcionamiento diferenciado respecto al Estado y al mercado.

En el momento actual, ambas vías sufren las carencias típicas de cada una de ellas, cuando se entienden en su forma «pura». La vía neo-lib/lab encuentra problemas cuando está en juego el nexo entre libertad-y-responsabilidad en las elecciones de los ciudadanos, porque el Estado mantiene el papel de quien no sólo hace las reglas, sino que tiende también a gestionarlas directamente, con el efecto de tener que estimular continuamente la actuación de los ciudadanos, que se han vuelto pasivos porque se han privatizado. De esta situación podría salirse recurriendo a formas de gobierno corporativo, pero, una vez más, se hace por evitarlo porque en vez de crear nuevos poderes diferenciados (como serían las Autoridades concebidas como expresiones de las autonomías sociales) se prefiere recurrir a una Administración Pública ya de por sí espesa. La vía societaria resuelve mejor el problema, pero encuentra dificultades en volver universales las esferas de la autonomía social, que sufren la tendencia a cerrarse en el particularismo, inducidas a él por la duradera regulación estructural de tipo neo-lib/lab, que las lleva a competir en juegos cuyo resultado final es cero. Por ello, debe incentivar los comportamientos universalistas y solidarios, es decir, conjugar la subsidiariedad con la solidaridad, pero no puede hacerlo si el contexto institucional no se lo permite.

En el próximo futuro, las vicisitudes del Estado del Bienestar probablemente estarán marcadas, desde el punto de vista empírico, por la necesidad de remediar los defectos de una vía y de la otra, encontrando formas de diferenciación de las intervenciones y un adecuado equilibrio entre ellas. 
En este escenario, las tendencias que parecen enfrentarse, en lo que concierne al gasto social, son: la reducción (simples recortes, más que racionalización) en determinados sectores en los que reside la fuerza política; en general, una disminución de las tasas de crecimiento de los gastos sociales, a lo largo de una curva logística (crecimiento hasta el límite), gestionada por una filosofía neo-lib/lab que tiende a configurar el Estado social como una especie de «red mínima de protección» para los más desfavorecidos (desarrollo sostenible). La apuesta consiste en comprender si, en dicho escenario, podrá o no nacer el nuevo ciclo histórico de la vía societaria, o bien si la inevitable crisis del Estado del Bienestar tradicional -en presencia de la competencia del interior y del exterior de Europa- dejará más bien el campo libre a una mercantilización del Bienestar, incluso con contribuciones significativas por parte de lo privado social y del sector terciario.

4.6. Para concluir: En la medida en que se consiguen ver los límites y los defectos estructurales del modelo neo-lib/lab, se abre camino la idea alternativa de una sociedad de la «solidaridad concurrente», o, como quisiera denominarla mejor, de la sociedad de la subsidiariedad solidaria. Ésta va más allá de la de una visión neo-lib/lab del Estado social y del Bienestar porque pone el acento en tres aspectos fundamentales. Primero, redefine el bienestar a partir de los sujetos, que son al mismo tiempo sus destinatarios y sus artífices. Segundo, asigna al Estado el papel político que le corresponde como expresión y garante del bien común, y por tanto como emanador de las reglas generales, pero no productor de una sociedad civil, o, peor aún, de un sistema de poder que contempla (que lee, interpreta y produce) la sociedad civil en función de la hegemonía política. Tercero, abandona la filosofía de la inclusión en un único orden institucional para abrazar la del fomento de una concurrencia solidaria entre múltiples pertenencias.

¿Por qué la visión societaria del bienestar, en la versión de subsidiariedad solidaria, es más humana? Básicamente, por tres razones. Primera, porque no sólo respeta las elecciones de libertad negativa (libertad de restricción), sino porque alimenta las elecciones de libertad positiva (libertad de fines sociales). Segunda, no obliga a la solidaridad por coacción, sino que la genera incentivando y premiando a quien adopta cauces de actuación que producen bienes relacionales. Tercera, no privilegia las soluciones de resultado o de competencia mercantil, sino las que apuntan a las construcciones de autonomías sociales capaces de combinar universalismo y particularidad.

Pasar del Estado del Bienestar a la Sociedad del Bienestar no es una operación que pueda ejecutarse con mecanismos políticos institucionales que funcionan en el marco de las negociaciones y de los compromisos entre mercado y democracia política, concediendo graciosos reconocimientos a lo privado social (reducido a un sector «terciario» residual o colonizado), forzado a pedir limosna o hacer presión de tipo sindical, y seguir tratando a las 
familias como si fuesen mendicantes. No significa mezclar aparatos estatales y agencias con ánimo de lucro y sin ánimo de lucro, que son sus clientes, «poniéndolos en red», como suele decirse. Significa, en cambio, emancipar a «otra» sociedad civil, con especialización de las funciones respecto a las de las instituciones políticas y de mercado.

La sociedad moderna se pregunta si el Estado social debía ser el todo o sólo una parte. En las ideologías y en las prácticas ha oscilado de un polo a otro, configurando el Estado como la síntesis del todo o, por el contrario, como subsistema residual. Por nuestra parte, corremos el peligro de seguir todavía dentro de este juego.

A la pregunta de qué nos deja como herencia la modernidad, de si «el Estado debe seguir siendo el todo o sólo una parte», el siglo XXI podría responder cambiando por completo la óptica y configurando el Estado como una función diferenciada del cuerpo político, especializada en controlar que los procesos sociales no creen pobreza y exclusión, sino riqueza y cohesión social. Va dirigido a todos (no sólo a los pobres), pero de ellos le interesa sólo lo que concierne a sus condiciones de participación, vistas como el resultado de una triangulación entre riesgos tomados, responsabilidades asumidas y oportunidades disfrutadas. Ello significa contemplar el Estado como ese subsistema específico que debe gobernar políticamente la sociedad, pero que no la debe sustituir, ni colonizar, ni producir. El Estado debe detenerse ante lo que no le pertenece, ante lo que no está disponible para él, como la esfera ética; debe ser un medio a través del cual la comunidad asume la responsabilidad colectiva de incluir en la vida social a quienes no pueden, o no logran, formar parte de ella.

La sociedad de la solidaridad subsidiaria tiene su forma política en lo que denomino el «Estado social relacional». ¿Qué es un Estado relacional? A mi entender, se caracteriza por los siguientes modos de configuración (figura 3):

1) El Estado relacional ya no se concibe como Vértice y Centro de la sociedad, sino como subsistema político-administrativo funcionalmente diferenciado para el gobierno de una sociedad que es observada y producida como «red» de sujetos e instituciones sociales (públicas, privadas y mixtas). En su aspecto institucional, el Estado resulta un conjunto de aparatos que gozan de funciones políticas y administrativas específicas, las cuales deben funcionar de manera subsidiaria $-\mathrm{y}$ relativamente simétrica en términos de poder- respecto de los otros subsistemas fundamentales de la sociedad, es decir, el mercado, la sociedad civil $^{7}$ y el subsistema de las familias y redes informales.

\footnotetext{
7 En este lugar, por sociedad civil entiendo las esferas del mundo asociativo (denominado «privado social» o, también, «sector terciario»), que no está constituido únicamente por organizaciones de voluntariado, sino por todas las formas de asociación social, incluidas las de la economía social y civil: ver Barber (1998); Donati (2000a, 2001b).
} 
2) El Estado relacional se configura como un ordenamiento jurídico y social que debe realizar la «ciudadanía compleja». La ciudadanía se dice compleja por tres órdenes de motivos:

i) Porque reconoce no sólo los derechos civiles, políticos y económico-sociales (hasta aquí llega T. H. Marshall), sino también los derechos humanos (los derechos de la persona en relación a las formaciones sociales en que ésta se desarrolla y desempeña sus actividades); se trata de cuatro «generaciones de derechos» diferentes, de las cuales la última se encuentra todavía en fase de definición.

ii) Porque entrelaza entre sí la ciudadanía estatal (la ciudadanía tradicional, definida como pertenencia del individuo al Estado nacional) y la ciudadanía societaria (definida como pertenencia de las personas a formas asociativas de sociedad civil que poseen un reconocimiento de sujetos colectivos — públicas, pero no estatales- que actúan con funciones políticamente relevantes en la esfera pública local, regional, nacional, supranacional), lo que hace posible la existencia de formas diferenciadas y múltiples de ciudadanía.

iii) Porque la ciudadanía compleja no se refiere sólo a los individuos, sino también a las formaciones sociales de sociedad civil (lo que constituye un motivo de fuerte discontinuidad con la modernidad). En efecto, desde el punto de vista sociológico, el Estado social relacional nace cuando las constituciones políticas típicamente modernas (de los siglos XIX y XX) se reforman a través de procesos de constitucionalización de las esferas privadas, es decir, de atribución de un valor político (que consiente decisiones colectivas vinculantes para el bien común), y las funciones públicas correspondientes, a organizaciones de carácter no-estatal.

El Estado relacional se des/centra y se articula «de forma asociacional (o federativa)», bien hacia arriba (por ejemplo, la Unión Europea), bien hacia abajo (comunidades locales y organizaciones de sociedad civil) ${ }^{8}$.

Las consecuencias sobre las políticas sociales son de enorme alcance. De hecho, el paso del Estado del Bienestar tradicional al Estado social relacional comporta, como mínimo, tres grandes cambios estructurales (fig. 4):

1) En primer lugar, cambia el código simbólico que preside las políticas de inclusión (o cohesión) social: el código simbólico predominante ya no es el estatal, sino que pasa a ser el que denomino código simbólico relacional.

8 En cuanto al concepto «asociacional», ver Hirst (1994, 1997, 1999). 
FIGURA 3

\section{Definición del Estado social relacional}

1. El Estado ya no es Centro y Vértice de la sociedad, sino que se convierte en un subsistema funcional subsidiario respecto de los otros tres subsistemas (mercado, sociedad civil, familias y redes informales).

2. El Estado tiene como objetivo la realización de la ciudadanía compleja, que posee tres características:

i) Reconoce e implementa cuatro esferas de derechos (civiles, políticos, sociales, humanos).

ii) Entrelaza ciudadanía estatal y ciudadanía societaria (permite formas diferenciadas y múltiples de ciudadanía).

iii) Otorga ciudadanía no sólo a los individuos, sino también a las formaciones sociales intermedias.

Dos configuraciones: Estado social tradicional y Estado social relacional

Código simbólico de la inclusión social
Ampliación de los derechos de ciudadanía estatal (bien como aumento de las prestaciones para quien es titular de ellas, bien como ampliación de las titularidades a cuotas anteriormente excluidas).
Realización de una ciudadanía compleja hacia abajo y hacia arriba como entrecruzamiento entre el código estatal (de pertenencia al Estado-nación) y el código societario (de pertenencia a esferas de sociedad civil).
Sujetos predominantes de las políticas sociales
Actores públicos.

Actores públicos, privados y mixtos: combinación del bienestar y bienestar societario plural (constitucionalización de las esferas privadas con funciones públicas).
Valores-guía
Libertad e igualdad (lib/lab) como valores rectores a partir de los cuales se hacen derivar las condiciones de la solidaridad.
Libertad, igualdad y solidaridad como valores diferenciados y simétricos (autonomía de la solidaridad social a través del reconocimiento de derechos relacionales y organizaciones que generan bienes relacionales).

2) En segundo lugar, las políticas sociales devienen una función difusa de la sociedad, es decir, una función que es perseguida por una pluralidad de actores, públicos y privados, combinados y entrelazados («relacionados») entre sí de varias formas — por ejemplo, en las configuraciones de la combinación del bienestar, del bienestar plural, en las concepciones societarias y multicontextuales (multistakeholder) de las organizaciones de bienestar, y otras más-.

3) En tercer lugar, las políticas sociales, que hasta ahora han sido redes basadas principalmente en los dos pilares de la libertad (lado lib o de mercado) y de la igualdad (lado lab 
o del Estado redistribuidor), deben institucionalizar un «tercer pilar», el de la solidaridad, como polo autónomo, distinto y no derivable de los otros dos. Hasta ahora, las políticas sociales han tratado la solidaridad como un subproducto de políticas perseguidas preferentemente a través de combinaciones de libertades individuales e igualdad de oportunidades en sistemas sociales concebidos como compromiso entre Estado y mercado, que denomino «sistemas lib/lab» ${ }^{9}$. No es casualidad que la solidaridad no figure todavía como valor y como finalidad en sí junto a los otros dos valores del plan maestro de la Unión Europea. Como ha afirmado Romano Prodi (2002, p. 20): «la interacción entre las fuerzas del libre mercado y de la competencia por un lado, y la igualdad de oportunidades para todos los ciudadanos por otro, es el plan maestro de la nueva construcción europea». El Estado social relacional es una nueva configuración de libertad, igualdad y solidaridad que no convierte en residual la solidaridad social, porque no la entiende como beneficencia, caridad o compensación para los más débiles y marginados, sino que la coloca en el mismo plano de la libertad y de la igualdad de oportunidades, incluso en términos de elaboración de derechos (los nuevos «derechos relacionales») y de producción de bienes y servicios (los nuevos «bienes relacionales») de prestación social.

En síntesis: el Estado social relacional es el que hace realidad una «ciudadanía compleja» que funciona a través de la revalorización del principio de relacionalidad aplicado al ámbito de las políticas sociales, en donde las políticas sociales no se entienden como políticas sectoriales para pobres y menesterosos, sino como una forma general de acción reflexiva de la sociedad respecto a sí misma, en términos de producción y distribución de todos los «bienes» sociales (en sentido amplio), sin separar entre sí las condiciones «normales» y las condiciones «particulares» (de riesgo, desviacionistas o patológicas).

La relacionalidad que caracteriza la ciudadanía compleja opera a todos los niveles territoriales y en todos los sectores de actuación, como ciudadanía que debe ser «ampliada» a todos los actores potenciales (no «beneficiarios» pasivos, sino sujetos activos que la eligen y la producen) (inclusive citizenship), y debe devenir "profunda», es decir, concreta y situada (deep citizenship). Las modalidades relacionales modifican de forma sustancial las características jerárquicas, burocráticas, asistenciales, disciplinarias, «laborales» (es decir, estrechamente dependientes del mercado del trabajo), que han sido típicas del Estado del Bienestar tradicional del siglo xx.

9 Un ejemplo paradigmático del sistema lib/lab es la denominada «tercera vía», teorizada por A. Giddens (1998), pero cabe subrayar que se trata solamente de una versión entre las muchas posibles (Donati, 2000b). 


\section{BIBLIOGRAFÍA DE REFERENCIA}

ANSPACH, M. R. (1996): «L'archipel du welfare américain: âge d'abondance, âge de pierre», en Revue du MAUSS, n. ${ }^{\circ}$, pp. 37-82.

ARENDT, H. (1964): Vita activa (ed. orig. 1958), Bompiani, Milano.

BARBER, B. R. (1998): A Place for Us. How to Make Society Civil and Democracy Strong, Hill and Wang, New York.

CAILLÉ, A. (1993): La démission des clercs. La crise des sciences sociales et l'oubli du politique, La Découverte, Paris (tr. it. Il tramonto del politico. Crisi, rinuncia e riscatto delle scienze sociali, Edizioni Dedalo, Bari, 1996).

CAILLÉ, A., et al. (1997): La democrazia del reddito universale, Manifestolibri, Roma.

CASADEI, B. (1997): «Le community foundations: una scelta strategica per le fondazioni delle casse di risparmio», en AA.VV., Fondazioni e organizzazioni non profit in Usa. Percorsi possibili per la realtà italiana, Maggioli, Rimini, pp. 171-186.

CLARKE, P. B. (1996): Deep Citizenship, Pluto Press, London-Chicago.

COX, R. H. (1998): «The Consequences of Welfare Reform: How Conceptions of Social Rights Are Changing», en Journal of Social Policy, vol. 27, Part. 1, pp. 1-16.

DAHRENDORF, R. (1994): «The Changing Quality of Citizenship», en B. van Steenberger (ed.), The Condition of Citizenship, Sage, London, pp. 10-19.

DONATI, P. (2000a): La cittadinanza societaria, Laterza, Roma-Bari (seconda edizione ampliata).

- (2000b): «Freedom vs. Control in Post-Modern Society: A Relational Approach», en E. K. Scheuch y D. Sciulli (eds.), Societies, Corporations and the Nation State, Brill, Leiden, The Annals of the International Institute of Sociology, vol. 7, pp. 47-76.

- (2001a): Il lavoro che emerge. Prospettive del lavoro come relazione sociale in una economia dopo-moderna, Bollati Boringhieri, Torino.

- (2001b): «La qualità civile del sociale», en P. Donati e I. Colozzi (a cargo de), Generare «il civile»: nuove esperienze nella società italiana, II Mulino, Bologna, pp. 23-57.

- (2002): «Ciudadanía y sociedad civil: dos paradigmas (ciudadanía lib/lab y ciudadanía societaria)», en REIS, n. ${ }^{\circ}$ 98/2, abril-junio, pp. 37-64.

— (2003): Sociologia delle politiche familiari, Carocci, Roma.

EISENBERG, M. A. (1995): «Relational Contracts», en J. Beatson y D. Friedmann (eds.), Good Faith and Fault in Contract Law, Clarendon Press, Oxford, pp. 292-304.

EUROPEAN COMMISSION (2002): Joint Report on Social Inclusion, EC, DGV, Bruxelles.

EVERS, A., y OLK, Th. (Hrsg.) (1996): «Konzepte und Strategien einer integrierten und synergetischen Sozialpolitik», en Wohlfahrtspluralismus, Westdeutcher Verlag, Opladen, pp. 126-141.

FALCK, H. (1994): La prospettiva dell'appartenenza nel lavoro sociale, tr. it., Vita e Pensiero, Milano (ed. orig.: Social Work: The Membership Perspective, Springer, Berlin-New York, 1988).

FAZZI, L., y MESSORA, E. (a cargo de) (1999): Modelli di welfare mix, Angeli, Milano. 
GIDDENS, A. (1998): The Third Way. The Renewal of Social Democracy, Polity Press, Cambridge (tr. it. La terza via. Manifesto per la rifondazione della socialdemocrazia, II Saggiatore, Milano, 1999).

HIRST, P. (1994): Associative Democracy. New Forms of Economic and Social Governance, Polity Press, Oxford.

— (1997): From statism to pluralism. Democracy, Civil society and Global Politics, UCL Press, London.

- (1999): «Associazionalismo: una strategia per l'inclusione», en Sociologia e Politiche Sociali, a. 2, n. ${ }^{\circ}$ 3, pp. 173194.

JONES, C. (ed.) (1993): New Perspectives on the Welfare State in Europe, Routledge, London y New York.

JUDGE, K. (1987): «The British welfare state in transition», en R. Friedmann, N. Gilbert y M. Sherer (eds.), Modern Welfare States, Wheatsheaf, London.

KEANE, J. (1988): Democracy and Civil Society, Verso, London.

KOSLOWSKI, P., y FOLLESDAL, A. (eds.) (1997): Restructuring the Welfare State. Theory and Reform of Social Policy, Springer, Berlin-New York.

LICHTERMAN, P. (2002): «Oltre la cittadinanza: di che cosa sono capaci le associazioni civili?», en Sociologia e Politiche Sociali, vol. 5, n. ${ }^{\circ}$, pp. 37-64.

LUHMANN, N. (1970): «Soziologie des politischen Systems», en Soziologische Aufklärung, Westdeutscher Verlag, Opladen, vol. I (tr. it. «La sociologia dei sistemi politici», en Illuminismo sociologico, II Saggiatore, Milano, 1983).

- (1995): «Inklusion/Exklusion», en Soziologische Aufklärung 6. Die Soziologie und der Mensch, Westdeutscher Verlag, Opladen.

- (1996): «Jenseits von Barbarei», en M. Miller y H.-G. Soeffner (hrsg.), Modernität und Barbarei. Soziologische Zeitdiagnose am Ende des 20. Jahrhunderts, Suhrkamp, Frankfurt a.M., pp. 219-230.

PRODI, R. (2002): «La mia visione dell'Europa», en C. D'Adda (a cargo de), Per l'economia italiana. Scritti in onore di Nino Andreatta, II Mulino, Bologna, pp. 13-31.

RAWLS, J. (1982): Una teoria della giustizia, tr. it., Feltrinelli, Milano.

ROTHSTEIN, B. (1998): Just Institutions Matter. The Moral and Political Logic of the Universal Welfare State, Cambridge University Press, Cambridge.

TAYLOR-GOOBY, P. (1989): «Current developments in the sociology of welfare», en British Journal of Sociology, vol. $10,{ }^{\circ} 4$, pp. 637-656.

TEUBNER, G. (1993): “The "State" of Private Networks: The Emerging Legal Regime of Polycorporatism in Germany», en Brigham Young University Law Review, n. ${ }^{\circ}$ 2, pp. 553-575.

- (1999): Diritto policontesturale: prospettive giuridiche della pluralizzazione dei mondi sociali, La Città del Sole, Napoli.

VAN DER VEEN, R. J. (1998): Participate or Sink. Threshold Equality Behind the Dykes, Paper presented at the ECPR Joint Sessions, University of Warwick, 23-28 March.

WEALE, A. (1983): Political Theory and Social Policy, Macmillan, London.

WILLKE, H. (1999): «The Necessity and Contingency of the State», en D. Baecker (ed.), Problems of Form, Stanford University Press, Stanford, California, pp. 142-154. 
According to the author, European societies continue to inspire social policies in a (state) inclusion code — which here we call lib/lab (a blend of liberalism and the labour movement) which was in the past a progress factor, but is now increasingly weaker and obsolete. Social policies find structural limits in their possibilities for innovation because they are drawn up as commitments between State and market, using the tertiary sector to remedy the failures of the other two sectors. In fact, social systems governed by lib/lab logics are headed for an irreversible crisis. This document illustrates the new trends for configuration of social policies, which here are called «societal». They are characterized by two main new developments: first, by the fact that they entrust social inclusion to a complex citizenry (conceived as an interlocking of state citizenry and societal citizenry), in which the collective subjects of civil society hold a fundamental role; second, because they define social welfare, services and rights through a symbolic code of a human relationships type. In terms of institutional order, an attempt is made to pass over to a «fourth Welfare State model», in other words, to a fourth generation social State, after having left behind the paternalistic, welfare and interventionist States. The author calls this the Human relationships social State.

Key words: Social Policy, Citizenship, Relational Inclusion, Relational Welfare State. 